\title{
ESTRUCTURA SOCIAL E IDENTIFICACION NACIONALISTA EN LA ESPAÑA DE LOS NOVENTA
}

\section{Gonzalo Herranz de Rafael}

Universidad de Almería

\begin{abstract}
RESUMEN
El presente estudio intenta avanzar algo más en los márgenes subjetivos de lo que se ha venido en llamar la conciencia nacionalista.

A partir de dos vías de estudio, uno descriptivo y otro explicativo, y partiendo de datos primarios procedentes de encuestas del CIRES, se ha pretendido demostrar o bien refutar dos hipótesis: en primer lugar, que la inexistencia de conciencia nacionalista supone la no existencia de nacionalismo en una nación existente o proyectada; en segundo lugar, que la estructura social del nacionalismo no tiene un perfil definido, ya que existen diferentes tipos de nacionalismos aun cuando los objetivos de todos ellos coincidan: conseguir la independencia o la autonomía político-cultural de su nación existente o proyectada.

Los datos han venido a demostrar dos hechos importantes: el primero es la inexistencia de conciencia nacionalista en España, y el segundo, el cual engloba ambas hipótesis, es que en España existe una nacionalidad dual o nacionalismo compartido, ya que la mayoría de los españoles se identifican tanto con España como de su región/nación de origen sean cuales sean sus condiciones ideológicas, religiosas, de clase, ocupacional, educativa, etc. Por otra parte, este dato nos hace suponer, y quizás sea la consecuencia más importante de la investigación, que existe una consolidación del sistema del Estado de las Autonomías.
\end{abstract}

\section{RECAPITULACIONES Y DEFINICIONES}

El nacionalismo como ideología y movimiento político social ha sido abordado desde muy diversas perspectivas, tanto teóricas como empíricas, y en

\section{Reis}


España, al inscribirse sociológicamente como un Estado plurinacional, los estudios empíricos sobre dicho tema han sido prolíficos desde los inicios de la Transición Democrática (Del Campo, Navarro y Tezanos, 1977; Jiménez Blanco, García Ferrando, Aranguren y Beltrán, 1977; García Ferrando, 1982; Aranguren, 1983; García Ferrando y Aranguren, 1991; García Ferrando, Aranguren y Beltrán, 1994).

La mayoría de estos trabajos, ya sea desde una vertiente descriptiva o explicativa, han partido del hecho de que el nacionalismo debe ser analizado teniendo en cuenta su composición estructural, es decir, a partir de sus componentes tanto objetivos (cultural, político y económico) como subjetivos (identificación o conciencia de pertenencia).

No obstante, todos coinciden en que este fenómeno hay que entenderlo desde una perspectiva multidimensional y, por lo tanto, las investigaciones sobre el mismo tendrían que centrarse en las diferentes dimensiones que lo conforman.

Aun dando por válida esta hipótesis, el presente estudio se va a centrar en la dimensión subjetiva de la identificación nacionalista por dos motivos: el primero, por la imposibilidad material que comporta un estudio de estas magnitudes al tener que abarcar todas sus dimensiones y, en segundo lugar, porque el análisis valorativo de la identificación nacionalista, y lo que se cree que significa implícitamente, puede cambiar y desplazarse con el tiempo, incluso en períodos cortos; de ahí su trascendencia ${ }^{1}$.

En este sentido, el nacionalismo, elemento esencial e impulsor de la creación de las naciones, es un fenómeno dual, construido desde arriba, pero que no puede entenderse a menos que se analice también desde abajo, es decir, por la base social, que además constituye el supuesto predictivo más importante a la hora de poder evaluar el éxito o fracaso de cualquier movimiento o acción nacionalista.

Entendemos que el surgimiento, organización y difusión de la conciencia nacionalista se establece en tres fases diferentes:

1. Creación de las bases ideológicas, por parte de una minoría que podríamos denominar intelligentsia, que, ante situaciones de conflicto, da el primer paso en la configuración nacionalista ${ }^{2}$.

2. Estos precursores inician el proceso de articulación de movimientos nacionalistas y campañas políticas a favor de su idea.

3. La conciencia nacionalista llega a las bases sociales, los programas obtienen el apoyo de las masas y se produce la revolución nacionalista, en los casos más extremos, o el voto mayoritario en los comicios electorales ${ }^{3}$.

1 La idea de la importancia de los estudios de la identificación nacionalista también se encuentra en E. J. Hobsbawn (1992: 19).

2 Una puesta al día sobre esta cuestión, J. Hutchinson y A. D. Smith (1994: 6).

3 Desde un punto de vista histórico, aunque bien pudiera valer en la actualidad, E. J. Hobsbawn (1992: 20) expone: "A propósito, la mayoría de los estudiosos estarían de acuerdo en que, 
El propósito de este trabajo es describir e intentar explicar la estructura subjetiva de la identificación nacionalista en España durante el primer cuarto de la década de los noventa a través de diferentes variables sociodemográficas, socioeconómicas y de diversos atributos, basándonos en encuestas del CIRES. Las hipótesis a corroborar son:

1. Que para que exista nacionalismo la mayoría de los nacionales deben identificarse con su nación existente o proyectada, inicialmente desde un plano subjetivo, para que posteriormente tenga significado, percepciones y actitudes nacionalistas; la no existencia de dicha identificación supondrá la inexistencia de nacionalismo en esa nación o comunidad.

2. Que la estructura social del nacionalismo no tiene un perfil definido, puesto que no se puede hablar de un solo tipo de nacionalismo, sino de una gama muy variada, aun cuando los objetivos de todos ellos sean conseguir la independencia o la autonomía política para su nación existente o proyectada; teniendo en cuenta que los medios utilizados para conseguir dicho objetivo esencial pueden ser diferentes en cada uno de los movimientos nacionalistas.

Sabiendo que España, tanto desde un punto de vista jurídico-político como sociológico, es un Estado plurinacional, el análisis del sentimiento nacionalista, abordado desde distintas variables socioeconómicas, sociodemográficas y de los atributos que describen las cualidades individuales de los encuestados, puede tener tres perfiles diferentes:

- Aquellos que se definen como nacionalistas, al sentirse exclusivamente como pertenecientes a las diferentes naciones y/o regiones del Estado español.

- Los que se identifican exclusivamente con la nación mayoritaria, es decir, la española, y por lo tanto se sienten españoles.

- Los que se consideran, en un plano de igualdad, españoles y de sus respectivas naciones $y / 0$ regiones de origen.

El efecto imaginado y sentido de que un grupo constituye una nación es explicado de forma concisa por el Teorema de Thomas, que indica que «si los individuos definen las situaciones como reales, son reales en sus consecuencias» ${ }^{4}$.

Efectivamente, el nacionalismo implica una conciencia colectiva que imprime una voluntad de acción al grupo nacionalista, que el individuo la interioriza y la amplía hacia el resto del grupo y, así, hace posible la reproduc-

cualquiera que sea la naturaleza de los primeros grupos sociales que la "conciencia nacional" capte, las masas populares — los trabajadores, los sirvientes, los campesinos— son las últimas en verse afectadas por ella.»

${ }^{4}$ Este teorema ha sido recogido por R. K. Merton (1980: 505). 
ción de esa conciencia nacionalista, sean o no objetivables los factores que delimitan el ser nacional'5.

En el caso de los nacionalismos que existen en el Estado español, la conciencia colectiva de lo nacional debe ser heterogénea ya que se supone abarca a la mayoría de los connacionales y, como partimos de una concepción plurinacional del Estado, las características de las diferentes identificaciones también deberán ser distintas.

La primera hipótesis propuesta se estudiará bajo una perspectiva descriptiva, viendo cuál es la posición de los españoles respecto a su sentimiento de pertenencia, tanto desde el punto de vista geográfico como nacionalista.

Respecto a la segunda, relacionaremos la variable identificación nacionalista con la estructura social española a través de variables sociodemográficas, socioeconómicas y determinados atributos para analizar cuál es el mapa nacionalista, si lo hubiera, del Estado español.

Por último, describiremos el perfil social de los que se definen como nacionalistas, en el supuesto que ello sea posible.

\section{VARIABLES Y ATRIBUTOS}

Los datos utilizados para este trabajo han sido sacados de las encuestas del CIRES desde enero de 1991 a 1994, ambos incluidos, siendo el tema de la encuesta la identificación supranacional.

\section{a) Muestras y Su ERror}

El tamaño de la muestra fue para todos los años de $\mathrm{N}=1.200$ sujetos mayores de 18 años de ambos sexos residentes en España. Las muestras son aleatorias, estratificadas por Comunidades Autónomas y municipios según tamaño. El margen de confianza para todas ellas fue del 95,5 por $100(2 \sigma)$, y el error muestral, para el caso más desfavorable, fue de $-+2,5$ para $1991 \mathrm{y}$ de $+-2,89$ para el resto de los años.

5 En muchos casos, cuando un grupo nacional o una comunidad tribal pierde algún aspecto de identificación, normalmente como consecuencia de acciones coactivas impuestas por la nación mayoritaria, el propio hecho que sustenta la conciencia colectiva determinará su unión y su resolución de seguir queriendo conseguir los objetivos propuestos. Los casos paradigmáticos, en el contexto del Estado español, de los catalanes y vascos durante la dictadura franquista son bien elocuentes. Véanse, para estos ejemplos, A. Pérez Agote (1986), para el vasco, y H. Fernández (1983), para el catalán. 


\section{b) VARIABLES Y RECODIFICACIONES}

\section{b.1) Identificación geográfica}

La pregunta, que fue la misma para todos los cuestionarios aplicados en los diferentes años de estudio, decía lo siguiente: «Todos nos sentimos más ligados a unos grupos que a otros. Concretamente, y de esta lista de espacios geográficos, ¿con cuál se siente más identificado? Es decir, se siente Vd. sobre todo ciudadano de: su pueblo o ciudad, su provincia, su Comunidad Autónoma, España, Europa, Occidente, El Mundo, ninguno, no sabe/no contesta.»

\section{b.2) Identificación nacionalista}

La pregunta, que fue la misma en todos los cuestionarios, decía lo siguiente: «En general, ¿diría Vd. que se siente más (extremeño, catalán, gallego, etc.) que español, tan (canario, etc.) como español, o más español que (valenciano, vasco, etc.)?» El ítem de identificación nacionalista en el cuestionario tiene siete categorías: sólo se siente (andaluz, vasco, etc.); más (valenciano, etc.) que español; tan (extremeño, etc.) como español; más español que (catalán, etc.); sólo se siente español; no sabe/no contesta. Estas categorías se recodificaron como: 1) nacionalistas; 2) identificación dual; 3) españolistas.

Con esta recodificación y después de diferentes pruebas se advirtió una gran pérdida de información, por lo que decidimos mantener la estructura inicial de la pregunta con sus siete categorías.

\section{b.3) Variables socioeconómicas}

b.3.1) Ocupación. La variable ocupación la utilizamos como ficticia (dummy) para el análisis de regresión, siendo codificada en dos categorías: manual y no manual. Por su singularidad se analizará por separado: variable manual y no manual, tomando los valores 0 y 1 .

b.3.2) Estudios. Esta variable se recodificó para el análisis de regresión estableciendo el número total de años de escolarización para cada una de las categorías, tomando el criterio siguiente: menos de estudios primarios, no sabe leer (cero años de escolaridad); menos de estudios primarios, sabe leer (dos años); estudios primarios completos, certificado escolar (ocho años); formación profesional de primer grado (nueve años); formación profesional de segundo grado (diez años); bachiller elemental (ocho años); bachiller superior (once años); estudios grado medio (quince años), y universitarios o técnicos de grado medio (diecisiete años). 
b.3.3) Renta. Se recodificó para el análisis de regresión estableciendo el valor medio de cada uno de los intervalos utilizando el siguiente criterio: 1 (30.000 pesetas); 2 (55.000 pesetas); 3 (87.000 pesetas); 4 (125.000 pesetas); 5 (175.000 pesetas); 6 (237.000 pesetas); 7 (307.000 pesetas); 8 (400.000 pesetas); 9 (500.000 pesetas).

\section{b.4) Variables sociodemográficas}

b.4.1) Hábitat. La variable hábitat se recodificó para el análisis de regresión estableciendo según lo siguiente: 1, urbano (más de 100.000 habitantes); 2, semiurbano (de 10.000 a 100.000 habitantes); rural (menos de 10.000 habitantes).

El resto de las variables sociodemográficas y atributos no fueron recodificados ya que se interpretan como cuantitativos, salvo algunos de ellos que sí lo fueron para el análisis descriptivo ${ }^{6}$.

\section{EL MODELO EXPLICATIVO}

\section{A) Estudios Descriptivos}

\section{a) La identificación geográfica}

La identificación geográfica nos permite acercarnos a la posición de los españoles respecto a su consideración primaria de pertenencia; y como puede apreciarse en la figura 1, para el año 1994, los españoles se definen mayoritariamente como localistas, tendencia que se mantiene en los diferentes años analizados, y en menor medida como de su nación y/o región, que es incluso inferior a la identificación con España ${ }^{7}$. Esta se sitúa muy cerca de un cuarto

${ }^{6}$ En realidad, esta forma de recodificar las variables nivel de estudios, renta y hábitat de cualitativas en cuantitativas tiene algunas contraindicaciones como es, por ejemplo, las pérdidas de datos y el alejarse de la realidad que pudiera describir los intervalos iniciales. De todas formas, al no incluirse estas variables como continuas inicialmente en el cuestionario del CIRES, la dispersión del dato se da de igual forma, aunque en menor medida que el efectuado por nosotros. Las variables continuas o cuantitativas se recodificaron para el análisis descriptivo, tanto la edad, la identificación ideológica y la práctica religiosa, aunque no fueron utilizadas posteriormente por tener un escaso valor estadístico.

7 Salvando diferencias metodologícas y conceptuales, ya los estudios realizados en España, en la década de los años setenta, sobre la conciencia regionalista (S. del Campo, M. Navarro y J. F. Tezanos, 1977: 122, 125) pusieron de manifiesto esta tendencia. El 59,6 por 100 de los encuestados se definía como localista, el 16,2 por 100 con su provincia (actualmente es algo menos de la mitad) y el 22,5 por 100 con su región. Aunque en esta primera pregunta no incluyeran la categoría de España, posteriormente en otra pregunta se le pedía al encuestado que se definiera sobre lo que era para él más importante, sobre su sentimiento de identificación, dando la posibilidad de dos preferencias; la primera preferencia era el identificarse como españoles $(55,4$ por $100)$ y de su región $(32,6$ por 100$)$, siendo la segunda de su región ( 46,0 por 100$)$ y españoles $(36,1$ por 100$)$. Con respecto a las tendencias más universalistas la identificación de los españoles no ha variado significativamente, siendo entonces y ahora insignificante. 


\section{FIGURA 1}

\section{Identificación geográfica}

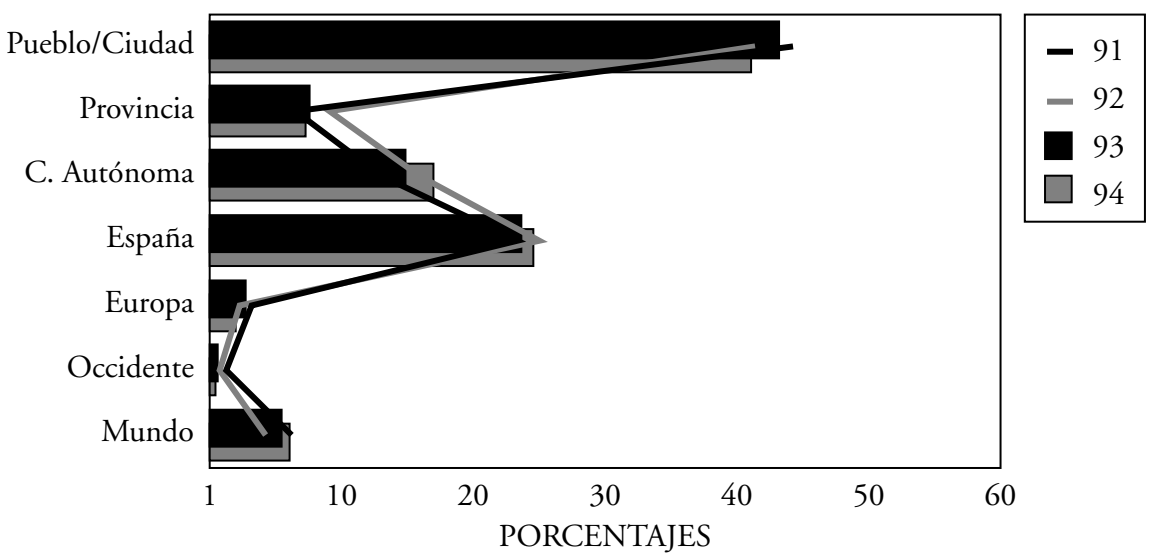

FUENTE: CIRES. Elaboración propia.

de la población, no habiendo marcadas diferencias con el resto de años analizados, lo que significa que las lealtades primarias, desde el punto de vista geográfico, no tienen por qué coincidir con aquellas que tienen una relación más inmediata y cercana al ciudadano, ya que la nación o/y región de origen ocupa la tercera preferencia de los encuestados.

Las actitudes más universalistas son casi inexistentes.

Por Comunidades Autónomas podemos observar que los más localistas son los pertenecientes a las Comunidades navarra, murciana y balear; existiendo una mayor identificación con la Comunidad Autónoma por parte de los catalanes, vascos, asturianos, canarios y gallegos, como se puede apreciar en la figura 2. Aunque el dato pueda llamar nuestra atención inicialmente, al coincidir con las tres Comunidades históricas, aparte de otras con alguna tradición nacionalista, los porcentajes son poco notables, aunque indicativos respecto al resto de las Comunidades Autónomas ${ }^{8}$.

${ }^{8}$ Uno de los primeros estudios que se realizaron en España sobre la conciencia nacionalista, y que ha marcado, desde el punto de vista teórico y metodológico, los posteriores análisis sobre el nacionalismo, fue el realizado bajo la dirección de J. Jiménez Blanco, M. García Ferrando, E. López Aranguren y M. Beltrán (1977: 47) En este estudio, teniendo en cuenta las distancias metodológicas y analíticas, la identificación con la región frente al exterior se da principalmente en Galicia (53 por 100), Canarias ( 49 por 100), País Vasco ( 47 por 100) y, en menor medida, en la Comunidad aragonesa (31 por 100) y catalana-balear (23 por 100). Las tendencias más españolistas se dieron en Castilla la Nueva (83 por 100), Madrid (81 por 100), Castilla la Vieja (77 


\section{FIGURA 2}

\section{Identificación geográfica por Comunidades Autónomas en 1994 (en porcentajes)}

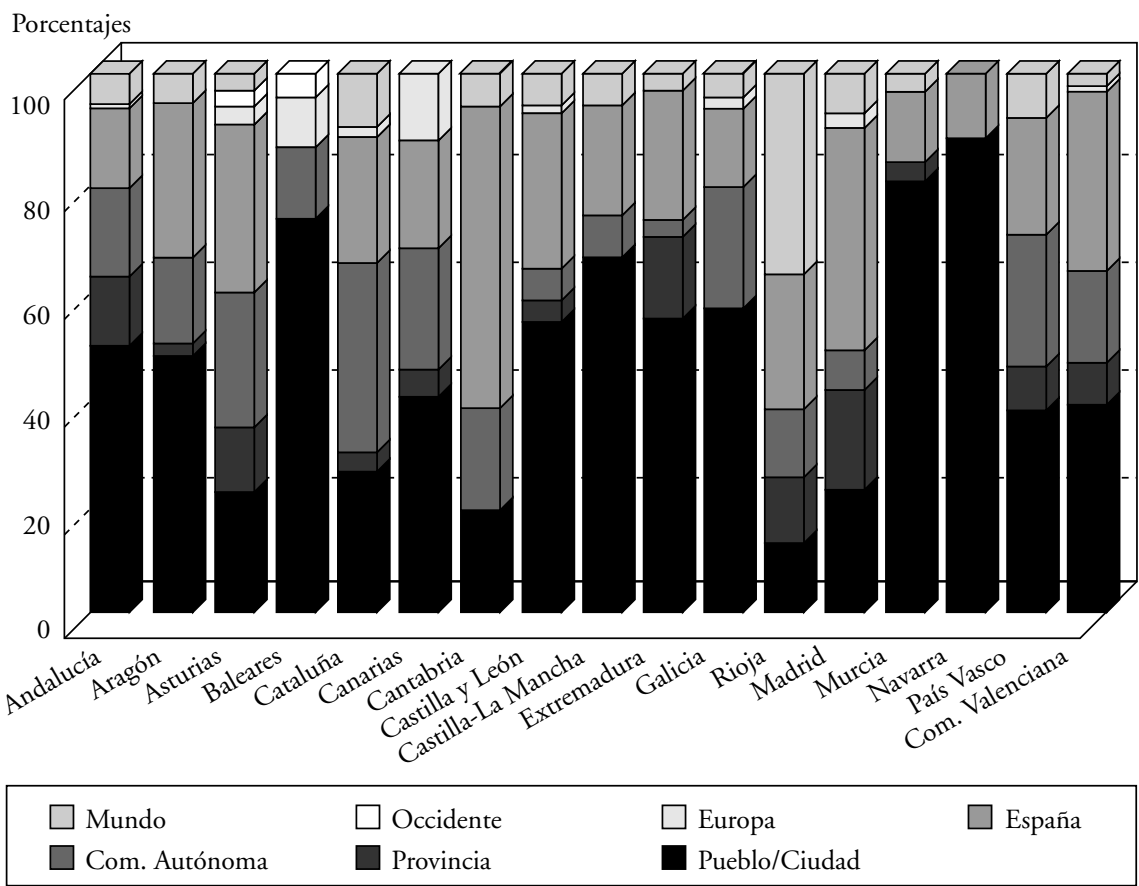

FUENTE: CIRES. Elaboración propia.

Para el resto de años estudiados no existen muchas diferencias, manteniéndose las tres comunidades históricas de forma casi constante, alternándose con otras comunidades según los años, como la de Cantabria y Asturias.

La distribución sociodemográfica y socioeconómica es escasamente indicativa respecto de la identificación geográfica?

por 100) y la Comunidad valenciana (72 por 100). Como se puede apreciar, la tendencia, salvo algunas excepciones como es el caso aragonés, se mantiene en cuanto al grado de identificación nacionalista por Comunidades Autónomas en el primer tercio de la década de los noventa.

9 El estudio de J. Jiménez Blanco, M. García Ferrando, E. López Aranguren y M. Beltrán (1977: 48) llega a la misma conclusión que nosotros, excepción hecha al tipo de hábitat y el nivel de estudio; así que, "los residentes en los estratos metropolitanos (grandes ciudades) tienden más que el resto (es decir, residentes en municipios menores) a sentirse como españoles... En cambio, el identificarse como de la región y como de la provincia (que es la segunda categoría que utilizan para analizar la identificación nacionalista frente al interior), respectivamente, es un fenómeno típico de los que no han realizado estudio alguno». 


\section{b) Identificación nacionalista}

Como indicábamos en la primera proposición, la identificación nacionalista es esencial para entender el nacionalismo en su primera vertiente, ya que si no hay una conciencia propia de identidad, raramente podremos afirmar que exista el nacionalismo y, en menor medida, que puedan articularse movimientos nacionalistas ${ }^{10}$.

Esta variable, al ser más directa, se acerca mucho más a la valoración sobre el nacionalismo, pues los encuestados debían tomar postura sobre su pertenencia a diferentes realidades nacionales. Como puede apreciarse en la figura 3, la mayoría se consideran igualmente españoles que de sus respectivas naciones y/o regiones (36,2 por 100), siendo la identificación sólo como español la segunda, con un 23,7 por 100 . Las posiciones más cercanas al nacionalismo periférico de tipo secesionista y/o irredentista son escasamente representativas.

Desde esta perspectiva hay que tener en cuenta que la mayoría de los movimientos nacionalistas periféricos del Estado español abogan por la independencia o, en su caso, la plena autonomía de sus Comunidades ${ }^{11}$.

Esta realidad incuestionable de la independencia puede observarse en algunos ejemplos ilustrativos, como en los principios políticos del Partido Nacionalista Vasco, quien en la Asamblea Nacional Extraordinaria de Zestoa afirma: «Euzko Alderdi Jeltzalea — Partido Nacionalista Vasco-, en su ya larga trayectoria, ha sido fiel a sus fines fundacionales, que tienen como objetivo la liberación de Euzkadi. Desde ese doble derecho [haciendo referencia a los derechos históricos de los Estados Vascos y al derecho de autodeterminación] y desde la renuncia al uso de la violencia, salvo en el orden defensivo, para la consecución de sus fines, Euzko Alderdi Jeltzalea ha

${ }^{10}$ En realidad, el modelo explicativo de la conciencia nacionalista está muy relacionado con el modelo marxista de la configuración de la conciencia de clase, en su clásica distinción entre «clase en sí» y "clase para sí» como paso previo para articularse organizaciones de clase que intenten defender los derechos e intereses de los trabajadores en el sistema capitalista. En el caso del nacionalismo, la conciencia de pertenencia es previa para poder articular movimientos nacionalistas. También es cierto que el nacionalismo surge como consecuencia de procesos conflictivos que vienen dados tanto por la articulación jurídico-político de los Estados, así como de tipo más sociológico, entendidos como la coacción de la nación mayoritaria respecto de las minoritarias y en ambos casos promovidos por una minoría, que podríamos denominar intelligentsia, que es, ante estas situaciones de conflicto, la que crea, organiza y difunde la conciencia nacionalista. Para una exposición de los planteamientos al respecto, G. Herranz (1992: 101) y J. Breuilly (1990: 41).

${ }^{11}$ Los niveles de independencia y de plena autonomía sólo podrán darse, desde nuestro punto de vista, desde dos premisas: o bien desde un Estado Federal donde se reconozca la soberanía de las diferentes naciones que conforman el Estado español inicialmente proyectado en el actual sistema de Organización Territorial del Estado de las Autonomías, o bien reformando los artículos 1.2 y 2 de la Constitución, donde se redefina la ubicación de la soberanía, que en este caso pasaría a las «naciones» que configuran el Estado de las Autonomías y no la nación española, como afirma el citado artículo 2 de la Constitución. 


\section{FIGURA 3}

\section{Identificación nacionalista}

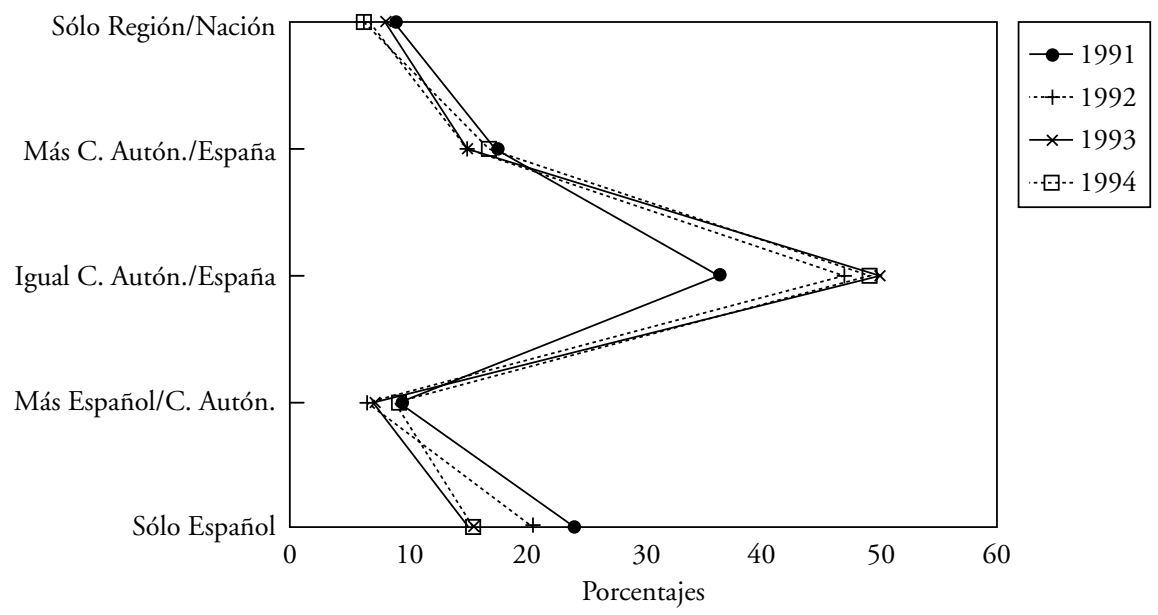

FUENTE: CIRES. Elaboración propia.

luchado por conseguir las máximas cotas de soberanía política que el juego de fuerzas ha permitido en cada momento", y más adelante concluye cuáles son sus objetivos y los motivos de la aceptación, inicial, de la Constitución española de 1978:

«Los planteamientos de fondo de Euzko Alderdi Jeltzalea para la aceptación del nuevo marco constitucional fueron básicamente los siguientes:

1. Reconocimiento de la soberanía del Pueblo Vasco, a partir de derechos históricos anteriores a la propia Constitución, reclamados ininterrumpidamente por el Pueblo Vasco.

2. Aceptación de una carta constitutiva de un marco vasco de poder político en los ámbitos legislativo, ejecutivo y judicial, que comprendiera a los cuatro territorios históricos.

En aquel momento político, no exigimos para la aceptación de la Constitución la inclusión del derecho de autodeterminación del Pueblo Vasco, principio que siempre hemos defendido y defenderemos, por parecernos más adecuada la fórmula "Pacto con la Corona" dado lo delicado de la coyuntura política..." (Asamblea Nacional Extraordinaria de Zestoa, Nacionalismo para el año 2000). 
P. W. Silver (1988), de forma más explícita, afirma: «tanto el antiguo como el nuevo nacionalismo vasco persiguen la independencia de España, por muy modulados que sean los tonos en que el PNV y EA formulen hoy esta petición».

En el mismo sentido, la ponencia de «Estrategia nacionalista para el futuro del autogobierno de Cataluña», expuesta en el VIII Congreso de Convergencia Democrática de Cataluña, expone en el punto 3.2 el «reclamar la soberanía que Cataluña necesita para ser plenamente una nación...» (Un Partido para la Cataluña de los años 90, 1989).

Desde una perspectiva más sociológica, F. Mercadé (1982), al analizar las aspiraciones de un grupo de intelectuales catalanes a través de su opinión acerca de cuál debe ser el proyecto político para España y Cataluña, dice, «a) tres de los entrevistados contemplan como proyecto la España de las Autonomías que consagra la Constitución; b) nueve entrevistados nos hablan del Estado federal o de la Confederación, y c) un último grupo de cuatro, propone la total independencia del Estado catalán ${ }^{12}$.

Ciñéndonos a los datos, podríamos afirmar que en España el nacionalismo es prácticamente inexistente, ya que éste debe ser entendido de manera excluyente, no cabiendo la identificación dual, como ocurre en el caso español. Los españoles se sienten tanto como tales y de sus respectivas naciones y/o regiones de origen, lo que es un signo favorable a la hora de entender la aceptación subjetiva del sistema de Organización Territorial del Estado de las Autonomías, pero ello no significa que exista un reconocimiento nacionalista ${ }^{13}$.

Por Comunidades Autónomas, como se puede apreciar en la figura 4, existen algunas variaciones significativas en los años estudiados, aunque se vislumbra una cierta tendencia bastante esclarecedora, porque la identificación propiamente nacionalista se produce tanto en el País Vasco como en la Comunidad catalana, situándose Galicia en segundo lugar en el año 1993 y, sorprendentemente, Andalucía en 1994.

La mayor actitud autonomista corresponde a la Comunidad catalana, a excepción del año 1993, en el que ocupa el primer lugar Andalucía, pasando esta Comunidad Autónoma al segundo puesto en el resto de los años analizados.

12 Asamblea Nacional extraordinaria de Zestoa, Nacionalismo para el año 2000 (40, 43); P. W. Silver (1988: 125); VIII Congreso de Convergencia Democrática de Cataluña, Un Partido para la Cataluña de los años 90 (1989: 48); F. Mercadé (1982: 156 a 216).

13 Es significativo que el último estudio publicado sobre la conciencia nacionalista denomine uno de los epígrafes del capítulo destinado a la identificación nacionalista/regionalista como «La doble identificación nacional/regional» (M. García Ferrando, E. López Aranguren y M. Beltrán, 1994: 15). En este estudio, que es resultado de una encuesta llevada a cabo en 1990, se confirma la tendencia de que la mayoría de los españoles se identifican con la doble nacionalidad o nacionalismo dual. En este sentido, más de la mitad de los españoles se identifican de esta forma (52 por 100), siendo la tendencia más españolista del 18 por 100 , el nacionalismo dual con predominio de la tendencia regional/nacional supone el 15 por 100 y de un 9 por 100 con predominio del españolismo, siendo la identificación del nacionalismo puro, de tipo secesionista o/y irredentista, solamente del 5 por 100. Se afianza, por tanto, la tendencia a la identificación dual a lo largo de la década de los noventa, estabilizándose en torno a la mitad de la población. 


\section{FIGURA 4}

\section{Identificación nacionalista por Comunidades Autónomas en 1994}

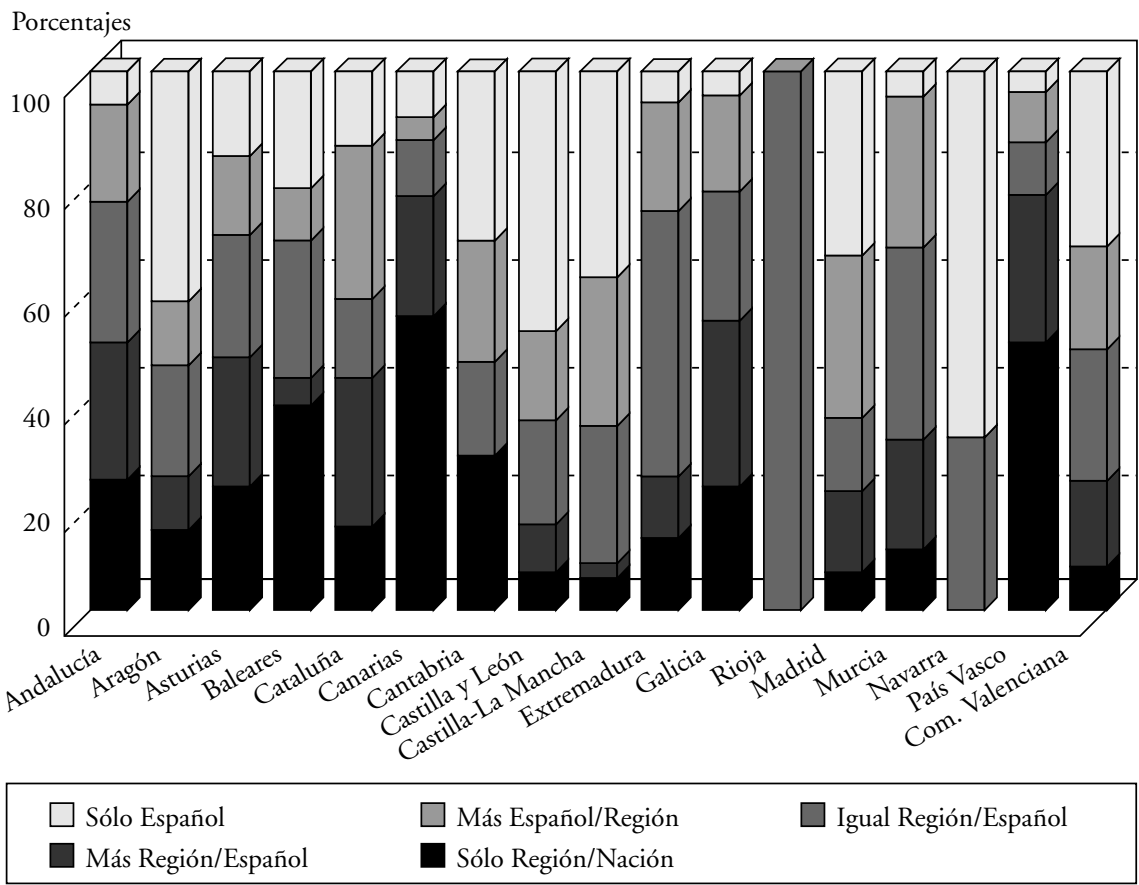

FUENTE: CIRES. Elaboración propia.

Lo más interesante lo encontramos en el País Vasco, donde se advierte un verdadero radicalismo en sus niveles de nacionalismo: los porcentajes en la categoría, «más (vasco, gallego, etc.) que español» son realmente bajos si los comparamos con la definición «exclusivamente vascos».

La doble nacionalidad se da fundamentalmente en Andalucía, Cataluña y, en menor medida, en la Comunidad de Madrid.

Las posiciones más españolistas están repartidas, centrándose especialmente en la Comunidad de Madrid, Castilla-León, Cataluña, País Valenciano, y por último, en Castilla-La Mancha ${ }^{14}$.

${ }_{14}$ El estudio de 1990 (M. García Ferrando, E. López Aranguren y M. Beltrán, 1994: 16), al analizar la distribución de la identificación nacionalista por Comunidades Autonómas, nos presenta un perfil casi idéntico al del resto de años analizados. Las posturas más españolistas se dan en las Comunidades Autónomas de Madrid (38 por 100), Castilla y León y Baleares (27 por 100), Valenciana (24 por 100) y Castilla-La Mancha (22 por 100). Por el contrario, el sentimiento 
Resumiendo, podríamos decir que la Comunidad Autónoma catalana es la que presenta un mayor mosaico de posturas que van del nacionalismo al españolismo, pasando por la identificación dual. En la Comunidad vasca se observa una cierta inclinación al radicalismo nacionalista y las posiciones autonomistas son escasas, al igual que ocurre con otros sentimientos de corte españolista.

Las Comunidades de Madrid, Castilla y León y País Valenciano son los mayores representantes de un españolismo más radical, lo cual tiene una explicación lógica en lo que respecta a Madrid, por ser la capital y foco de atracción de migraciones del resto de regiones del Estado.

El nacionalismo, aunque minoritario, se distribuye esencialmente por las tres Comunidades históricas, no existiendo prácticamente en el resto del Estado español.

Podríamos concluir diciendo que la conciencia nacionalista se desarrolla de forma desigual tanto desde el punto de vista de los grupos sociales como por las regiones de un Estado.

Además, y como ocurriera con el análisis de la valoración geográfica, las variables independientes sociodemográficas, socioeconómicas y atributos apenas tienen significación, ya que las tendencias son poco relevantes, en el sentido de que en todos los grupos de población el sentimiento dominante es la doble nacionalidad ${ }^{15}$.

\section{B) Estudios EXPLICATIVOS}

En una aproximación al estudio descriptivo hemos observado que en el Estado español el nacionalismo no tiene cabida para la gran mayoría de la población, lo que podría traducirse como la práctica inexistencia de sentimientos de pertenencia a una nación diferenciada, distinta a la mayoritaria, es decir, la española, aunque sí hay un reconocimiento explícito de la Comunidad Autónoma como forma de representación cultural y política de la región y/o nación, acentuándose especialmente en las Comunidades con derechos históricos.

nacionalista puro se sitúa especialmente en el País Vasco (20 por 100), Cataluña (14 por 100) y Canarias (12 por 100). Como es de esperar, la identificación dual es mayoritaria en todas las Comunidades Autónomas, aunque especialmente en Cantabria (83 por 100), Murcia (68 por 100), Extremadura y Andalucía (62 por 100) y, en menor medida, en el País Vasco (35 por $100)$, Cataluña (36 por 100) y Madrid (42 por 100). Con respecto a nuestro estudio se mantiene la centralidad del nacionalismo etnocultural en el País Vasco, aunque todavía sin una definición clara si nos atenemos a los datos.

15 A esta misma conclusión llega el estudio de M. García Ferrando, E. López Aranguren y M. Beltrán (1994: 18), estableciendo alguna excepción con los perfiles de los dos nacionalismos opuestos: los españolistas (18 por 100) serían grupos de personas con más de 60 años y con nivel de estudio que no sobrepasa los primarios, mientras que los nacionalistas étnicos (5 por 100) se situarían con niveles universitarios e identificados con la clase social media-alta. 
La posibilidad de que surjan movimientos políticos y sociales de base etnocultural, políticamente incluyentes, es factible desde el momento de la plena aceptación del modelo de organización del Estado de las Autonomías.

Aun teniendo en cuenta que el nacionalismo ocupa una posición poco relevante en el Estado español, bajo el punto de vista valorativo, pretendemos ahora explorar cuál es su composición social partiendo del análisis de algunas variables sociodemográficas, socioeconómicas y atributos, e intentando cuantificar, si es posible, una relación lógica entre ellos.

Como se puede apreciar en las tablas $1-a), b$ ), c) —, respecto de las correlaciones para los diferentes años analizados existe una cierta significación esta-

\section{TABLA 1}

\section{Correlaciones de Pearson en 1991}

Variables

\begin{tabular}{|c|c|c|c|c|c|c|c|c|c|c|}
\hline & (1) & (2) & (3) & (4) & (5) & (6) & (7) & (8) & (9) & (10) \\
\hline (1) & - & $0,1264^{* *}$ & 0,0113 & 0,0049 & 0,0175 & $-0,0232$ & 0,0648 & $-0,0126$ & 0,0094 & $-0,0443$ \\
\hline (2) & & & $0,1145^{*}$ & 0,0117 & $0,3651^{* *}$ & 0,0393 & 0,0027 & $-0,1606^{* *}$ & 0,0678 & $-0,0131$ \\
\hline (3) & & & & $-0,4433^{* *}$ & $0,2646^{* *}$ & $0,1093^{*}$ & $-0,1825^{* *}$ & $0,2411^{* *}$ & $0,0765^{*}$ & $0,1220^{* *}$ \\
\hline (4) & & & & & $-0,1413^{* *}$ & $-0,2162^{* *}$ & * $0,3484^{* *}$ & $-0,4172^{* *}$ & 0,0863 & $-0,4102^{* *}$ \\
\hline (5) & & & & & & $0,1557^{* *}$ & ${ }^{*}-0,0986^{*}$ & $-0,0013$ & $0,1589^{* *}$ & * 0,0476 \\
\hline (6) & & & & & & & $-0,1867^{* *}$ & $0,1325^{* *}$ & $-0,0175$ & 0,0667 \\
\hline (7) & & & & & & & & $-0,2042^{* *}$ & 0,0203 & $-0,2870^{* *}$ \\
\hline (8) & & & & & & & & & $-0,0276$ & $0,1521^{* *}$ \\
\hline (9) & & & & & & & & & & $-0,3645^{* *}$ \\
\hline
\end{tabular}

* Significación menor que 0,01.

** Significación menor de 0,001.

NotA: Las variables utilizadas son las siguientes: (1) Identificación nacionalista, (2) Identificación políticoideológica, (3) Edad, (4) Educación, (5) Práctica religiosa, (6) Hábitat, (7) Ingresos, (8) Clase social subjetiva, (9) Trabajo manual, (10) Trabajo no manual.

\begin{tabular}{|c|c|c|c|c|c|}
\hline Variables & $N$ & Media & $\begin{array}{c}\text { Desviación } \\
\text { estándar }\end{array}$ & Minimo & Máximo \\
\hline Identificación nacionalista ........ & 1.167 & 3,30 & 1,32 & 1 & 6 \\
\hline Identificación ideológica .......... & 697 & 3,45 & 1,40 & 1 & 7 \\
\hline 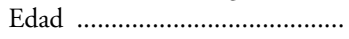 & 1.200 & 43,17 & 17,38 & 18 & 94 \\
\hline 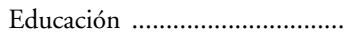 & 1.200 & 7,69 & 4,66 & 0,00 & 17,00 \\
\hline 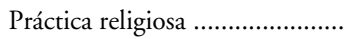 & 1.142 & 2,57 & 1,35 & 1 & 5 \\
\hline 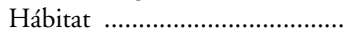 & 1.200 & 1,81 & 0,81 & 1,00 & 3,00 \\
\hline 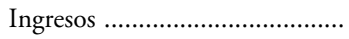 & 1.200 & 98217,08 & 87489,65 & 0,00 & 500000 \\
\hline 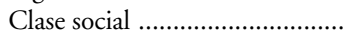 & 1.179 & 3,43 & 0,93 & 1 & 8 \\
\hline 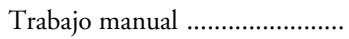 & 1.193 & 0,69 & 0,46 & 0,00 & 1,00 \\
\hline Trabajo no manual ....................... & 1.193 & 0,81 & 0,39 & 0,00 & 1,00 \\
\hline
\end{tabular}


TABLA 1.a)

Correlaciones de Pearson en 1992

Variables

\begin{tabular}{|c|c|c|c|c|c|c|c|c|c|c|}
\hline & (1) & (2) & (3) & (4) & (5) & (6) & (7) & (8) & (9) & (10) \\
\hline (1) & - & 0,0218 & 0,0482 & $-0,0134$ & $-0,0206$ & $-0,0528$ & $-0,0569$ & 0,0267 & 0,0455 & $0,0876^{*}$ \\
\hline (2) & & & 0,0598 & $0,1306^{* *}$ & $0,3255^{*}$ & $-0,0473$ & 0,0262 & $-0,1396^{* *}$ & 0,0724 & $-0,0191$ \\
\hline (3) & & & & $-0,4347^{* *}$ & $0,2310^{* *}$ & 0,0415 & $-0,2140^{* *}$ & $0,2529^{* *}$ & $0,1822^{* *}$ & * $0,1665^{* *}$ \\
\hline (4) & & & & & $-0,0562$ & $-0,2147^{* *}$ & $0,3207^{* *}$ & $-0,3145^{* *}$ & 0,0848 & $-0,4033^{* *}$ \\
\hline (5) & & & & & & 0,0624 & $-0,1296^{* *}$ & $-0,0228$ & $0,1491^{\text {** }}$ & k 0,0163 \\
\hline (6) & & & & & & & $-0,1820^{* *}$ & $0,1600^{* *}$ & $-0,0247$ & 0,0471 \\
\hline (7) & & & & & & & & $-0,2357^{* *}$ & $-0,0940^{*}$ & $-0,2627^{* *}$ \\
\hline (8) & & & & & & & & & 0,0050 & $0,1380^{* *}$ \\
\hline (9) & & & & & & & & & & $-0,2873^{* *}$ \\
\hline
\end{tabular}

* Significación menor que 0,01 .

** Significación menor de 0,001 .

NotA: Las variables utilizadas son las siguientes: (1) Identificación nacionalista, (2) Identificación políticoideológica, (3) Edad, (4) Educación, (5) Práctica religiosa, (6) Hábitat, (7) Ingresos, (8) Clase social subjetiva, (9) Trabajo manual, (10) Trabajo no manual.

\begin{tabular}{|c|c|c|c|c|c|}
\hline Variables & $N$ & Media & $\begin{array}{l}\text { Desviación } \\
\text { estándar }\end{array}$ & Minimo & Máximo \\
\hline Identificación nacionalista ........ & 1.183 & 3,20 & 1,18 & 1 & 6 \\
\hline Identificación ideológica .......... & 755 & 3,33 & 1,45 & 1 & 7 \\
\hline 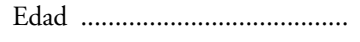 & 1.200 & 44,81 & 18,12 & 18 & 93 \\
\hline 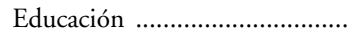 & 1.200 & 7,64 & 4,51 & 0,00 & 17,00 \\
\hline Práctica religiosa ............................ & 1.152 & 2,64 & 1,38 & 1 & 5 \\
\hline 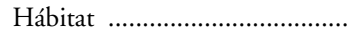 & 1.200 & 1,86 & 0,82 & 1 & 3 \\
\hline 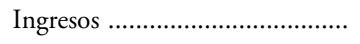 & 1.200 & 97569,17 & 87108,84 & 0,00 & 500000 \\
\hline Clase social ........................................ & 1.194 & 3,48 & 0,80 & 1 & 8 \\
\hline 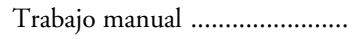 & 1.199 & 0,76 & 0,43 & 0,00 & 1,00 \\
\hline Trabajo no manual ......................... & 1.199 & 0,83 & 0,38 & 0,00 & 1,00 \\
\hline
\end{tabular}


TABLA 1.b)

Correlaciones de Pearson en 1993

\section{Variables}

\begin{tabular}{|c|c|c|c|c|c|c|c|c|c|}
\hline & (1) & (2) & (4) & (5) & (6) & (7) & (8) & (9) & (10) \\
\hline (1) & - & 0,0861 & $0,1115^{*}-0,0740$ & 0,0786 & $-0,1357^{* *}$ & ${ }^{*}-0,0020$ & 0,0589 & $-0,0003$ & $-0,0235$ \\
\hline (2) & & & $0,2116^{* *}-0,0418$ & $0,3754^{* *}$ & $-0,0366$ & 0,0086 & $-0,0411$ & $0,0922^{*}$ & $-0,0006$ \\
\hline (3) & & & $-0,4438^{* *}$ & $0,3164^{* *}$ & 0,0116 & $-0,1531^{* *}$ & * $0,2361^{* *}$ & $0,2383^{* *}$ & * $0,1607^{* *}$ \\
\hline (4) & & & & $-0,1640^{* *}$ & ${ }^{*}-0,2103^{* *}$ & * $0,1882^{* *}$ & ${ }^{*}-0,3426^{* *}$ & $-0,0201$ & $-0,3568^{* *}$ \\
\hline (5) & & & & & 0,0885 & $-0,0316$ & 0,0529 & $0,2178^{* *}$ & * 0,0666 \\
\hline (6) & & & & & & $-0,0777$ & $0,1945^{* *}$ & $-0,0509$ & 0,0865 \\
\hline (7) & & & & & & & $-0,1732^{* *}$ & $-0,0701$ & $-0,1698^{* *}$ \\
\hline (8) & & & & & & & & 0,0714 & $0,1352^{* *}$ \\
\hline (9) & & & & & & & & & $-0,2431^{* *}$ \\
\hline
\end{tabular}

* Significación menor que 0,01 .

** Significación menor de 0,001.

NotA: Las variables utilizadas son las siguientes: (1) Identificación nacionalista, (2) Identificación políticoideológica, (3) Edad, (4) Educación, (5) Práctica religiosa, (6) Hábitat, (7) Ingresos, (8) Clase social subjetiva, (9) Trabajo manual, (10) Trabajo no manual.

\begin{tabular}{|c|c|c|c|c|c|}
\hline Variables & $N$ & Media & $\begin{array}{l}\text { Desviación } \\
\text { estándar }\end{array}$ & Mínimo & Máximo \\
\hline Identificación nacionalista ........ & 1.169 & 3,08 & 1,13 & 1 & 6 \\
\hline Identificación ideológica ........... & 733 & 3,47 & 1,46 & 1 & 7 \\
\hline 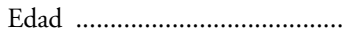 & 1.200 & 44,94 & 17,92 & 18 & 93 \\
\hline 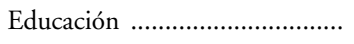 & 1.200 & 7,72 & 4,15 & 0,00 & 17,00 \\
\hline Práctica religiosa ............................ & 1.146 & 2,71 & 1,39 & 1 & 5 \\
\hline 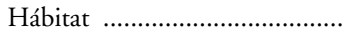 & 1.200 & 1,85 & 0,82 & 1,00 & 3,00 \\
\hline 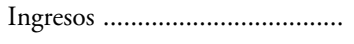 & 1.200 & 84476,85 & 78515,98 & 0,00 & 500000 \\
\hline 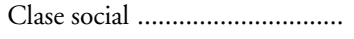 & 1.187 & 3,53 & 0,90 & 1 & 8 \\
\hline Trabajo manual ........................... & 1.200 & 0,74 & 0,44 & 0,00 & 1,00 \\
\hline Trabajo no manual ......................... & 1.200 & 0,87 & 0,34 & 0,00 & 1,00 \\
\hline
\end{tabular}


TABLA 1.c)

Correlaciones de Pearson en 1994

Variables

\begin{tabular}{|c|c|c|c|c|c|c|c|c|c|c|}
\hline & (1) & (2) & (3) & (4) & (5) & (6) & (7) & (8) & (9) & (10) \\
\hline (1) & - & 0,0155 & 0,0549 & $-0,0364$ & $0,0831^{*}$ & 0,0051 & $-0,0405$ & $0,1093^{* *}$ & 0,0494 & 0,0717 \\
\hline (2) & & & $0,1610^{*}$ & $* *-0,0647$ & $0,3014^{* *}$ & 0,0111 & $-0,0014$ & $-0,0204$ & $0,1968^{*}$ & 0,0235 \\
\hline (3) & & & & $-0,4003^{* *}$ & $0,3478^{* *}$ & 0,0322 & $-0,1796^{* *}$ & $0,1709^{* *}$ & $0,1641^{* *}$ & * $0,1126^{* *}$ \\
\hline (4) & & & & & $-0,1473^{* *}$ & $-0,1350^{* *}$ & $0,3272^{* *}$ & $-0,2956^{* *}$ & 0,0264 & $-0,3916^{* *}$ \\
\hline (5) & & & & & & $0,0989^{*}$ & $-0,0775$ & 0,0184 & $0,1764^{* *}$ & * $0,1312^{* *}$ \\
\hline (6) & & & & & & & $-0,1561^{* *}$ & $0,1866^{* *}$ & $-0,0073$ & $0,0832^{*}$ \\
\hline (7) & & & & & & & & $-0,1999^{* *}$ & $-0,0617$ & $-0,3393^{* *}$ \\
\hline (8) & & & & & & & & & 0,0052 & $0,1508^{* *}$ \\
\hline (9) & & & & & & & & & & $-0,2338^{* *}$ \\
\hline
\end{tabular}

* Significación menor que 0,01 .

** Significación menor de 0,001 .

NotA: Las variables utilizadas son las siguientes: (1) Identificación nacionalista, (2) Identificación políticoideológica, (3) Edad, (4) Educación, (5) Práctica religiosa, (6) Hábitat, (7) Ingresos, (8) Clase social subjetiva, (9) Trabajo manual, (10) Trabajo no manual.

\begin{tabular}{|c|c|c|c|c|c|}
\hline Variables & $N$ & Media & $\begin{array}{l}\text { Desviación } \\
\text { estándar }\end{array}$ & Minimo & Máximo \\
\hline Identificación nacionalista ........ & 1.187 & 3,12 & 1,11 & 1 & 6 \\
\hline Identificación ideológica ........... & 835 & 3,51 & 1,39 & 1 & 7 \\
\hline 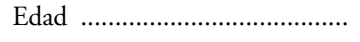 & 1.200 & 45,03 & 18,01 & 18 & 92 \\
\hline 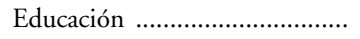 & 1.200 & 7,57 & 4,34 & 0,00 & 17,00 \\
\hline Práctica religiosa ............................ & 1.170 & 1,76 & 0,85 & 1 & 3 \\
\hline 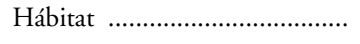 & 1.200 & 1,86 & 0,82 & 1 & 3 \\
\hline 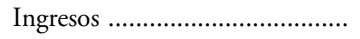 & 1.200 & 95758,33 & 83704,52 & 0,00 & 500000 \\
\hline Clase social ........................................ & 1.192 & 3,55 & 0,91 & 1 & 8 \\
\hline 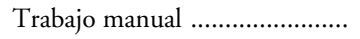 & 1.199 & 0,74 & 0,44 & 0,00 & 1 \\
\hline Trabajo no manual ....................... & 1.199 & 0,88 & 0,32 & 0,00 & 1 \\
\hline
\end{tabular}


dística, más intensa en unos casos que en otros, entre la posición nacionalista de los encuestados y su identificación ideológica (1991), la ocupación no manual (1992), el tamaño del hábitat (1993), la clase social subjetiva (1994) y, en menor medida, la edad (1993) y la práctica religiosa (1994).

Desde la perspectiva de dichas correlaciones podemos destacar lo siguiente:

1. Todas las variables antes citadas están directamente correlacionadas con la conciencia nacionalista —a excepción del tamaño del hábitat, que lo está en sentido inverso-, por lo que al elevar la identificación ideológica, edad, hábitat y clase social lo hace el sentimiento nacionalista.

2. Los niveles de variación conjunta de las variables son escasas y, así por ejemplo, y para el caso más favorable, entre la identificación ideológica y la nacionalista es sólo de 1,4 por 100 .

Inicialmente nos centraremos en estas variables para los años a estudiar, teniendo que rechazar el resto, por no poseer relación con la variable en cuestión.

Aun cuando el nivel de correspondencia es mínimamente significativo, nuestro interés es poder llegar a saber cuál es el perfil social de la conciencia nacionalista y, avanzando un poco más, cuantificar la relación existente entre esta conciencia y las variables utilizadas.

En conjunto, la conciencia nacionalista tiene, bajo la perspectiva social, un perfil poco claro, y lo que demuestran los modelos de ecuaciones (véanse tablas 2 a 5) es que hay un escaso nivel de explicación por parte de las variables elegidas respecto de la identificación nacionalista.

De todas formas, y siguiendo la ortodoxia explicativa en este tipo de análisis (Mauro F. Guillen, 1992), nos centraremos en la interpretación de los parámetros estimados más significativos, particularizando caso por caso:

a) La variable identificación ideológica (tabla 2) posee cierto nivel explicativo respecto de la conciencia nacionalista en:

1. El valor de la constante $(2,859)$ en la primera ecuación (X1) nos indica que si solamente tenemos en cuenta la influencia de esta variable, y si el resto valiera cero, los individuos se definen con nacionalidad compartida.

2. A medida que avanzamos en la escala de identificación ideológica (recordando que la posición 1 de la escala correspondería a la extrema izquierda y 10 a la extrema derecha), aumenta la nacionalista hacia tendencias más españolistas.

3. Si desarrollamos la ecuación de regresión para este caso observamos que $^{16}$ :

16 La fórmula general de la ecuación de regresión múltiple es la siguiente: $Y=B 1+$ $\mathrm{B} 2 \times 2+\mathrm{B} 3 \times 3+\ldots+\mathrm{Bk} \times \mathrm{k}+\mathrm{U}$, de donde para estos casos serían: $\mathrm{Y}=2,859+0,112(\mathrm{x} 2)$; siendo, por ejemplo, los valores de $\mathrm{x}=3,5,7 ; 3,195 ; 3,419 ; 3,643$, respectivamente. 


\section{TABLA 2}

Modelo de regresión de la identificación nacionalista en 1991

\begin{tabular}{|c|c|c|c|c|c|c|c|c|c|}
\hline Ecuación regresión $V$. indepen. & $X 1$ & $X 2$ & X3 & $X 4$ & $X 5$ & $X 6$ & $\times 7$ & $X 8$ & X9 \\
\hline Corr. mult. & 0,119 & 0,120 & 0,120 & 0,130 & 0,131 & 0,148 & 0,146 & 0,147 & 0,152 \\
\hline Constante & 2,859 & 2,901 & 2,905 & 2,904 & 2,904 & 2,860 & 2,805 & 2,752 & 2,945 \\
\hline Iden & $\begin{array}{l}0,112 \\
(3,13)\end{array}$ & $\begin{array}{l}0,113 \\
(3,15)\end{array}$ & $\begin{array}{l}0,114 \\
(3,14)\end{array}$ & $\begin{array}{l}0,130 \\
(3,34)\end{array}$ & $\begin{array}{l}0,130 \\
(3,33)\end{array}$ & $\begin{array}{l}0,129 \\
(3,30)\end{array}$ & $\begin{array}{l}0,129 \\
(3,24)\end{array}$ & $\begin{array}{l}0,129 \\
(3,26)\end{array}$ & $\begin{array}{l}0,129 \\
(3,26)\end{array}$ \\
\hline
\end{tabular}

Edad

Estudios

Práctica religiosa

$$
\begin{array}{llllll}
-0,040 & -0,038 & -0,034 & -0,030 & -0,027 & -0,025 \\
(-0,95) & (-0,89) & (-0,81) & (-0,70) & (-0,64) & (-0,59)
\end{array}
$$

Hábitat

$$
\begin{array}{lllll}
-0,032 & -0,019 & -0,026 & -0,029 & -0,033 \\
(-0,49) & (-0,29) & (-0,40) & (-0,45) & (-0,50)
\end{array}
$$

Renta

Clase social subjetiva

$$
\begin{array}{lll}
0,018 & 0,028 & 0,026
\end{array}
$$$$
(0,24) \quad(0,38) \quad(0,36)
$$

Trabajo manual

Trabajo no manual

NotA: Los datos del T-test están entre paréntesis.

Los espacios indican un insignificante valor estadístico.

3.1. Tanto los individuos que se definen como de extrema izquierda y de centro, ya sea de izquierda o de derecha, se sienten de nacionalidad compartida.

3.2. Cuanto más nos acercamos a las categorías derechistas (posición 7 de la escala en adelante), la identificación se establece en más españolista que de la región de origen; pero nunca esta categoría se muestra excluyente. 
Lo más interesante es que este dato rompe la creencia inicial de que los que se sitúan en las posiciones más extremas de la derecha se consideran exclusivamente españoles, confirmando la idea de una mayor aceptación por todos los españoles del modelo autonómico.

b) La variable ocupación no manual (tabla 3) tiene trascendencia respecto a la conciencia nacionalista en:

1. El valor de la constante es de 2,759, al igual que en el caso anterior, y siempre suponiendo que el resto de las variables tienen valor cero, la mayoría

\section{TABLA 3}

Modelo de regresión de la identificación nacionalista en 1992

\begin{tabular}{|c|c|c|c|c|c|c|c|c|c|}
\hline Ecuación regresión $V$. indepen. & $X 1$ & $X 2$ & $X 3$ & $X 4$ & $X 5$ & $X 6$ & $X 7$ & $X 8$ & X9 \\
\hline 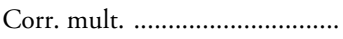 & 0,038 & 0,065 & 0,066 & 0,068 & 0,083 & 0,103 & 0,108 & 0,110 & 0,144 \\
\hline Constante & 3,073 & 2,922 & 2,964 & 3,027 & 3,191 & 3,293 & 3,221 & 3,166 & 2,759 \\
\hline Identificación política ................... & $\begin{array}{l}0,031 \\
(1,06)\end{array}$ & $\begin{array}{l}0,028 \\
(0,95)\end{array}$ & $\begin{array}{l}0,030 \\
(0,99)\end{array}$ & $\begin{array}{l}0,029 \\
(0,90)\end{array}$ & $\begin{array}{l}0,027 \\
(0,85)\end{array}$ & $\begin{array}{l}0,029 \\
(0,89)\end{array}$ & $\begin{array}{l}0,029 \\
(0,88)\end{array}$ & $\begin{array}{l}0,026 \\
(0,82)\end{array}$ & $\begin{array}{l}0,023 \\
(0,71)\end{array}$ \\
\hline Edad ............. & & - & - & - & - & - & - & - & - \\
\hline 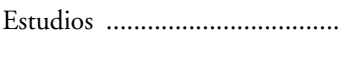 & & & - & - & - & - & - & - & $\begin{array}{l}0,010 \\
(0,81)\end{array}$ \\
\hline Práctica religiosa ........... & & & & $\begin{array}{l}-0,040 \\
(-1,19)\end{array}$ & $\begin{array}{l}-0,037 \\
(-1,08)\end{array}$ & $\begin{array}{l}-0,042 \\
(-1,23)\end{array}$ & $\begin{array}{l}-0,040 \\
(-1,18)\end{array}$ & $\begin{array}{l}-0,040 \\
(-1,18)\end{array}$ & $\begin{array}{l}-0,040 \\
(-1,18)\end{array}$ \\
\hline Hábitat . & & & & & $\begin{array}{l}-0,069 \\
(-1,27)\end{array}$ & $\begin{array}{l}-0,079 \\
(-1,46)\end{array}$ & $\begin{array}{l}-0,089 \\
(-1,62)\end{array}$ & $\begin{array}{l}-0,086 \\
(-1,57)\end{array}$ & $\begin{array}{l}-0,076 \\
(-1,40)\end{array}$ \\
\hline Renta & & & & & & - & - & - & - \\
\hline Clase social subjetiva & & & & & & & $\begin{array}{l}0,026 \\
(0,42)\end{array}$ & $\begin{array}{l}0,026 \\
(0,42)\end{array}$ & $\begin{array}{l}0,027 \\
(0,43)\end{array}$ \\
\hline 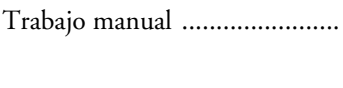 & & & & & & & & $\begin{array}{l}0,098 \\
(0,91)\end{array}$ & $\begin{array}{l}0,183 \\
(1,63)\end{array}$ \\
\hline Trabajo no manual .. & & & & & & & & & $\begin{array}{l}0,312 \\
(2,47)\end{array}$ \\
\hline 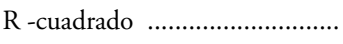 & 0,0015 & 0,0042 & 0,0044 & 0,0047 & 0,0070 & 0,0106 & 0,0118 & 0,0123 & 0,0208 \\
\hline
\end{tabular}

NotA: Los datos del T-test están entre paréntesis.

Los espacios indican un insignificante valor estadístico. 
de los encuestados se creen tanto españoles como de sus respectivas Comunidades Autónomas.

2. Existe una mayor identificación nacionalista por aquellos que tienen una ocupación no manual que manual, siendo ésta bastante significativa $(0,312)$, dentro de lo que cabe, si lo comparamos con el resto de las variables analizadas.

c) La variable hábitat (tabla 4). Su alcance explicativo respecto de la conciencia nacionalista es:

1. El valor de la constante es de 3,191, por lo que si el resto de variables intervinientes valieran cero, se sitúa claramente en la identificación dual.

\section{TABLA 4}

Modelo de regresión de la identificación nacionalista en 1993

\begin{tabular}{|c|c|c|c|c|c|c|c|c|c|}
\hline Ecuación regresión $V$. indepen. & $X 1$ & $X 2$ & X3 & $X 4$ & X5 & $X 6$ & $x 7$ & $X 8$ & X9 \\
\hline Corr. mult. & 0,071 & 0,119 & 0,124 & 0,134 & 0,200 & 0,200 & 0,208 & 0,212 & 0,222 \\
\hline Constante ... & 2,834 & 2,612 & 2,742 & 2,673 & 3,191 & 3,177 & 2,875 & 2,900 & 3,182 \\
\hline Identificación & $\begin{array}{l}0,055 \\
(1,93)\end{array}$ & $\begin{array}{l}0,039 \\
(1,33)\end{array}$ & $\begin{array}{l}0,040 \\
(1,38)\end{array}$ & $\begin{array}{l}0,044 \\
(1,42)\end{array}$ & $\begin{array}{l}0,037 \\
(1,20)\end{array}$ & $\begin{array}{l}0,037 \\
(1,19)\end{array}$ & $\begin{array}{l}0,040 \\
(1,29)\end{array}$ & $\begin{array}{l}0,039 \\
(1,27)\end{array}$ & $\begin{array}{l}0,038 \\
(1,24)\end{array}$ \\
\hline
\end{tabular}

Edad

Estudios

$$
\begin{array}{lllllll}
-0,010 & - & -0,019 & -0,019 & -0,015 & -0,014 & -0,020 \\
(-0,93) & & (-1,67) & (-1,69) & (-1,31) & (-1,18) & (-1,62)
\end{array}
$$

Práctica religiosa

$\begin{array}{llllll}0,022 & 0,036 & 0,036 & 0,036 & 0,043 & 0,047 \\ (0,64) & (1,04) & (1,04) & (1,07) & (1,23) & (1,35)\end{array}$

Hábitat

Renta

Clase social subjetiva

Trabajo manual 
2. El hábitat está inversamente asociado a la conciencia nacionalista, por lo que tiene un efecto negativo sobre la misma, en el sentido de que los individuos que viven en poblaciones semiurbanas y rurales se autodenifen como más cercanos a posiciones nacionalistas, mientras que en las zonas urbanas disminuye dicha tendencia.

3. De todas formas, si desarrollamos la ecuación de regresión, observamos para cada una de las categorías utilizadas (hábitat urbano, semiurbano y rural) la misma tendencia de identificación con la nacionalidad compar$\operatorname{tida}^{17}$.

d) La clase social subjetiva (tabla 5) sigue el mismo comportamiento que el resto de las variables anteriormente analizadas, y las conclusiones arrojadas son idénticas, el nacionalismo dual es el dominante.

Aun cuando lo realmente significativo es la tendencia a la identificación dual en todas las categorías de autoposición de clase, se observa que a medida que descendemos en la escala, hacia situaciones de media-baja y baja, los individuos presentan una conciencia dual más acentuada y, por lo tanto, más alejada de tendencias más nacionalistas.

e) Práctica religiosa (tabla 5). Aunque con un nivel de significatividad insignificante $(0,064)$, la mayoría de los católicos, tanto practicantes como no practicantes, se definen como nacionalistas duales.

Lo únicamente interesante es que a medida que descendemos en la escala de práctica religiosa (donde 1 sería nada practicante y 5 muy practicante), la opinión se acerca más a posiciones españolistas, aunque en este caso sólo podamos establecer dicha tendencia ${ }^{18}$.

A modo de resumen, podríamos decir que:

1. Tanto la identificación ideológica (tabla 2), la ocupación no manual (tabla 3), el hábitat (tabla 4), así como la clase social subjetiva y la práctica religiosa (tabla 5), tienen unos niveles de significación bastante bajos.

2. La dirección de la asociación es para todos los casos la misma, es decir, positiva, excepción del hábitat, en que es negativa aunque con distinta fuerza, lo que ya observamos en las tablas de correlaciones - véanse tablas $1 . a), b), c)$ -

17 La fórmula general de la ecuación de regresión múltiple es: $\mathrm{Y}=\mathrm{B} 1+\mathrm{B} 2 \mathrm{X} 2+$ $\mathrm{B} 3 \mathrm{X} 3 \ldots \mathrm{BKxK}+\mathrm{U}$, de donde para este caso sería $\mathrm{Y}=3,191-0,214(\mathrm{X} 2)$; siendo para los tres tipos de hábitat analizados los valores $\mathrm{X}=1,2,3$ (donde el valor 1 corresponde al tipo de población urbana «más de 100.000 habitantes», el valor 2 se refiere a poblaciones semiurbanas «entre 10.000 y 100.000 habitantes", y el valor 3 corresponde a poblaciones rurales "con menos de 10.000 habitantes»), siendo, respectivamente, $2,977,2,763$ y 2,543 .

${ }_{18}$ Por ejemplo, desarrollando la ecuación de regresión múltiple, para el valor de $\mathrm{X}=5$ (muy practicante) sería: $Y=2,950+0,064 \times 5=3,27$. 


\section{TABLA 5}

Modelo de regresión de la identificación nacionalista en 1994

\begin{tabular}{lrrrrrrrrr}
\hline Ecuación regresión V. indepen. & $X 1$ & $X 2$ & $X 3$ & $X 4$ & $X 5$ & $X 6$ & $X 7$ & $X 8$ & $X 9$ \\
\hline Corr. mult. ..................................... 0,020 & 0,057 & 0,058 & 0,089 & 0,089 & 0,093 & 0,140 & 0,143 & 0,156 \\
Constante ............................... & 3,040 & 2,909 & 2,946 & 2,950 & 2,965 & 3,000 & 2,480 & 2,451 & 2,149
\end{tabular}

Identificación política

$$
0,016
$$

$-\quad-$

Edad

Estudios

Práctica religiosa

$$
\begin{array}{llllll}
0,064 & 0,064 & 0,064 & 0,069 & 0,066 & 0,057 \\
(1,96) & (1,96) & (1,95) & (2,10) & (1,98) & (1,72)
\end{array}
$$

Hábitat

$$
\begin{array}{rrrr}
-0,012 & -0,034 & -0,033 & -0,031 \\
(-0,24) & (-0,68) & (-0,66) & (-0,64)
\end{array}
$$

Renta

Clase social subjetiva

Trabajo manual

Trabajo no manual

R -cuadrado $\begin{array}{lllllllll}0,0004 & 0,0033 & 0,0034 & 0,0080 & 0,0080 & 0,0088 & 0,0196 & 0,0206 & 0,0245\end{array}$

NotA: Los datos del T-test están entre paréntesis.

Los espacios indican un insignificante valor estadístico.

3. Aunque algunas variables y atributos posean mayor alcance explicativo, siempre siendo conscientes de su limitación, lo importante y a tener en cuenta es que la constante, en los tres modelos y diferentes ecuaciones, arroja un valor establecido en la categoría definida como identificación dual. 
4. Apreciamos que el valor de variación de la conciencia nacionalista respecto de las variables independientes elegidas es mínima en todas las ecuaciones, ya que, como se puede apreciar en la tabla 4, representando ésta la más favorable, sólo es del 4,94 por 100 .

5. El sentimiento nacionalista es para la mayoría de los españoles dual, lo que hace imposible establecer un perfil social claro respecto de individuos que se definen como nacionalistas o como españoles. Los espanoles se sienten por igual de España y de su nación/región de origen; ya sean políticamente de izquierdas, centro o derecha, vivan en zonas rurales o urbanas, se definan como católicos — practicantes o no-, se consideren de clase alta o baja y tengan especialmente una ocupación no manual.

\section{CONCLUSIONES}

Siendo conscientes de las limitaciones que comportan este tipo de análisis comparativos, en términos generales se puede afirmar que:

1. Si entendemos por nacionalismo un movimiento que sustenta una ideología cuyos fines son, o bien la consecución de la independencia o la autonomía de una nación proyectada, o bien la preservación de la esencia cultural y particularista de una nación objetiva (G. Herranz, 1992), hemos podido observar, siguiendo la lógica de los datos, que la mayoría de los encuestados tienden a definirse como españoles y de su región y/o nación de origen, por lo que el sentimiento nacionalista no existe; lo que sí se puede constatar, desde una perspectiva exploratoria, es la consolidación del nuevo sistema de Organización Territorial del Estado de las Autonomías.

2. Los ciudadanos que han nacido y residen en las Comunidades históricas son los que adoptan unas posturas más cercanas al nacionalismo, aunque con porcentajes poco relevantes. Este dato se confirma en todas las investigaciones realizadas sobre la conciencia nacionalista desde la segunda mitad de la década de los años setenta.

En realidad, donde se vislumbra un sentir nacionalista más arraigado es en el País Vasco, donde la definición de pertenencia como «exclusivamente vasco» es la que tiene una mayor trascendencia.

3. Una inicial aproximación al estudio analítico del primer cuarto de la década de los noventa coincide plenamente con el análisis descriptivo, ya que en el Estado español el nacionalismo es prácticamente inapreciable. Lo que existe es una identificación dual o nacionalidad compartida que rompe tanto tendencias pannacionalistas de corte españolista como nacionalistas de tipo 
secesionista. Se vuelve a confirmar, por tanto, la legitimación del nuevo Estado de las Autonomías.

Podríamos decir que, consuetudinariamente, el nacionalismo en muchos casos, y España no es una excepción, se trata de un movimiento apoyado de forma minoritaria en contra de la apatía y, a menudo, incluso de la hostilidad de la mayoría del cuerpo social nacional en cuyo nombre actúan los nacionalistas.

4. El nacionalismo, en el Estado español, se encuentra en una segunda fase de desarrollo (véase página 10 de este trabajo), no siendo interiorizada la conciencia nacionalista por las bases sociales.

5. En general, podemos afirmar que dicha identificación dual está relacionada, aunque escasamente, con la ideología, la clase social subjetiva, el hábitat, la práctica religiosa y la ocupación.

Deducimos que, para los años analizados, dicha posición dual o nacionalidad compartida se consolida, dentro de la relatividad de los datos, con más vigor cuanto más nos aproximemos a:

a) Ideológicamente, todos los individuos, sea cual sea su adscripción, aunque con mayor fuerza a aquellos que se sitúan en el centro, ya sea de izquierda o derecha.

b) Individuos que residen en cualquier tipo de hábitat, siendo más fuerte este tipo de identificación compartida en las zonas urbanas y semiurbanas que en las rurales.

c) Individuos pertenecientes a cualquier clase social, aunque más claramente a medida que descendemos hacia posiciones media-baja y baja.

d) Individuos practicantes y no practicantes desde el punto de vista religioso, acercándose los que dicen ser muy practicantes a posturas más españolistas.

e) Individuos que normalmente desempeñan su actividad en el sector no manual.

Este perfil es extensible a la gran mayoría de los españoles, puesto que los datos suelen acumularse en las categorías medias, lo que corrobora nuestra hipótesis de la inexistencia de identificación nacionalista en España.

6. Respecto de las definiciones político-ideológicas, en aquellos que se sitúan en posiciones de la derecha su valoración es más cercana a la categoría «más español que (gallego, riojano, etc.)» que a la de «sólo español». Lo que se aleja de la creencia de un sentimiento exclusivamente españolista tan arraigado en este sector político.

7. Partiendo del hecho que los niveles de relación y significación entre las variables elegidas y la conciencia nacionalista son insignificantes y que, por lo 
tanto, no hemos podido llegar a establecer ningún tipo de explicación lógica de cuál sería la estructura social nacionalista en España, hemos podido corroborar al menos (y éste ha sido el motivo central de no desechar totalmente la investigación), por dos vías diferentes, la tendencia identificativa de la mayoría de los españoles con la nación mayoritaria y su región/nación de origen. Constatación, por otra parte, que debería abrir nuevas vías de estudio tanto desde la vertiente teórica del nacionalismo como de la empírica.

Lo realmente reseñable es poder llegar a explicar si esta tendencia de sentimiento compartido puede llegar a definirse e inscribirse en la ortodoxia teórica nacionalista como una variante más o es un mero efecto de tipo coyuntural con escasos visos de continuidad.

\section{BIBLIOGRAFIA}

Asamblea Nacional EXtraordinaria de Zestoa: Nacionalismo para el año 2000.

Breuilly, J. (1990): Nacionalismo y Estado, Barcelona, Pomares-Corredor.

Convergencia Democrática de Cataluña. Un Partido para la Cataluña de los años 90, VIII Congreso (1989).

Del campo, S.; Navarro, M., y Tezanos, F. (1977): La cuestión regional española, Madrid, Edicusa.

GARCÍA Ferrando, M. (1982): Regionalismo y autonomía en España (1976-1979), Madrid, CIS.

García Ferrando, M.; López Aranguren, E., y Beltrán, M. (1994): La conciencia nacional y regional en la España de las autonomías, Madrid, CIS.

Guillén, M. F. (1992): Análisis de regresión múltiple, Madrid, CIS (Cuadernos Metodológicos).

HernándeZ, F. (1983): La identidad nacional en Cataluña, Barcelona, Vicens-Vives.

Herranz DE RAFAel, G. (1992): La vigencia del nacionalismo, Madrid, CIS/Siglo XXI.

HobSBAWN, E. J. (1992): Naciones y nacionalismo desde 1780, Barcelona, Crítica.

Hutchinson, J., y Smith, A. D. (eds.) (1994): Nationalism, Oxford/Nueva York, Oxford University Press.

Jiménez Blanco, J.; García Ferrando, M.; López Aranguren, E., y Beltrán Villalva, M. (1977): La conciencia regional en España, Madrid, CIS.

LÓPEZ ARAnguren, E. (1983): La conciencia regional en el proceso autonómico español, Madrid, CIS.

López Aranguren, E., y García Ferrando, M. (1991): «Nacionalismo y regionalismo en la España de las Autonomías», en J. Vidal Beneyto (comp.), España a debate. La sociedad, Madrid, Tecnos, pp. 115-136.

MERCADÉ, F. (1982): Cataluña: intelectuales politicos y cuestión nacional, Barcelona, Península.

Merton, R. K. (1980): Teoría y estructura social, México, Fondo de Cultura Económica.

PÉRez AGOTE, A. (1986): La reproducción del nacionalismo. El caso Vasco, Madrid, CIS.

Silver, P. W. (1988): Nacionalismos y transición. Euskadi, Catalunya, España, San Sebastián, Txertoa. 


\begin{abstract}
The purpose of this study is to explore the subjective limits of what has come to be known as the "nationalist conscience».

Based on two types of study, one descriptive and one explanatory, and drawing on primary data from CIRES surveys, the author attempts to prove or reject two hypotheses: first, that the non-existence of nationalist awareness implies the non-existence of nationalism in an existing or projected nation; second, that the social structure of nationalism does not respond to a clearlydefined profile in as much as different types of nationalism exist even if their ultimate objectives are the same, namely to achieve the independence or political-cultural autonomy of the existing or projected nation.

The data collected attest to two key facts: firstly, that there is no nationalist conscience in Spain, and secondly — and this encompasses both hypotheses - that a dual nationality or shared nationalism exists in Spain since most Spaniards identify both with Spain and their region/ country of origin, irrespective of their ideology, religious beliefs, class, professional and educational status, etc. On the other hand, this fact gives us reason to believe - and this is perhaps the most important finding of this research study - that there is a consolidation of the system of the estado de las autonomías (state of autonomies)
\end{abstract}

